\title{
Korrespondenzen.
}

\section{Bemerkungen zu Prof. Franz Keibels Kritik.}

\author{
Von Dr. Arnold Brass in Godesberg.
}

Die Darlegungen Prof. Keibels in No. 8 dieser Wochenschrift enthalten Angriffe, die zumeist durchaus unberechtigt und nebenher geeignet sind, meine Person und meine Kenntnisse in ein zweifelhaftes Licht zu setzen.

Die Hunderte deutscher Aerzte, die mich persönlich kennen, werden schlankweg die Behauptung, daß ich religiös-fanatisch wäre, als durchaus unzutreffend hinstellen. Nicht ich vermengte Naturforschung und Weltanschauung miteinander, sondern der sogenannte moderne Monist tat und tut dies. Ich habe ausdrücklich bemerkt, daB es eine undankbare Aufgabe sei, dieser Richtung entgegentreten zu müssen.

Daß ich den von Prof. Keibel gezeichneten Schaf-Embryo mit einem von Prof. Bonnet gezeichneten verwechselte, ist eine Flüchtigkeit meinerseits.

Prof. Keibel behauptet: ich kenne die Zahl der Ursegmente nicht (den Ausdruck „Urwirbel“ gebraucht er übrigens selbst wiederholt im Handbuch der Entwicklungslehre). Die Segmentierung des Körpers habe ich seit $1882 \mathrm{mehr}$ denn einmal in meinen Vorträgen als eine solche bezeichnet, welche innerlich viel weiter geht, als es änßerlich in den Ursegmenten hervortritt! In dem Praktikum der Embryologie, das uns 1877-78 Prof. Ra u b er in aufopferungsvollster Weise gab, haben wir auch diese Frage, neben jener der Mesodermbildung, der Allantois- und Blutentstehung praktisch bearbeitet. Auf die Segmentierung im allgemeinen kam es mir aber im "AffenProblem" nicht an, sondern - das muj Keibel auf den ersten Blick gesehen haben - auf den falsch gezeichneten, um etwa 10 Wirbel zu lang dargestellten Schwanz des MenschenEmbryos. Hier kam die Wirbelsäule in Betracht, und die, das weiß Keibel so gut wie ich, kann man nach den überliegenden, äußerlich sichtbaren Ursegmenten glatt abzählen!|!

Ich verstehe beim besten Willen nicht, was Prof. Keibel eigentlich mit der Beanstandung der Zahl 33 bezweckt; andere Anatomen haben sie sofort verstanden; in der Hisschen Figur treten äußerlich, vom Kopf $a b$, so viele Ursegmente hervor, deshalb ist sie nicht "genau kopiert."

Mit der Angabe, daß ich den Primitivstreifen des Menschenkeims nicht kennen soll, hat Prof. Keibel noch weniger Glück, denn über den Embryo, den Graf Spee mitteilte, habe ich zum Teil schriftlich und auch in Vorträgen referiert und ebenso 1898 in einer Arbeit ausdrücklich die Primitivrinne mit dem Primitivstreifen für den Menschen anerkannt! Nur eine Stelle kann Keibels Angabe notdurftig rechtfertigen; die habe ich selbst erst muhsam suchen müssen. Auf S. 53 der Broschüre "Ernst Haeckel als Biologe" sage ich: Sobald sich der Keim aus zwei Zellschichten rein kugelschalenförmig entwickelt hat, entsteht hinten auf der elliptischen Scheibe, in der Richtung der großen Achse, eine kleine Furche (Primitivrinne). Welchen Zweck sie hat, das wissen wir vorläufig nicht; ob sie beim Menschen vorhanden ist, das wissen wir noch weniger, denn die ersten Entwicklangsstadien des Menschen hat bis heute noch keines Menschen Auge zu sehen bekommen, trotz der schönen Abbildungen, die Haeckel seinen gläubigen Lesern immer wieder als beweisende Tatsachen davon vorzusetzen liebt. Ich habe, das sieht jeder ein, der unbefangen liest, von den ersten Stadien gesprochen und auf $\mathrm{Haeckels}$ Darstellungen hingewiesen. Zudem erkenne ich den "Sandalenkeim", den Haeckel nach Graf Spee abbildet, ausdrücklich als sachlich richtig an, mit den Worten: "Die oberste Reihe wellen wir gelten lassen."

Von oben herunteĩ wird schließlich auch die Darstellung, welche ich von der Entstehung des Blutes und der Gefäße skizzenhaft gab, als "Entdeckung" hervorgehoben und abgefertigt. - Ich werde doch wohl auch das Recht haben, so gut wie jeder Forscher meiner Meinung Ausdruck geben zu dürfen. Ich stelle diese ausdrücklich als meine persönliche Meinung hin, als "Auszüge aus noch nicht veröffentlichten größeren Arbeiten ". Ich gebe sie damit der wissenschaftlichen Kritik preis, aber nicht der einfachen Verspottung; die

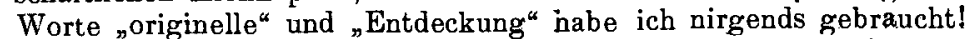

Gerade die Beschimpfungen, die mir Haeckel vor Abfassung der Broschüre zuteil werden ließ, haben es verhindert, daB ich mit 
Prof. Keibel brieflich über einige Fragen verhandelte, die mich seit langem interessieren und mit der Segmentierung des Kopfes, der Ausbildung der dort zuerst auftretenden Gefäße und der Entstehung der Kopfkrümmungen im engen Zusammenhange stehen. Ich bedauere, da $\beta$ ich meiner brieflichen Anfrage keine voll aufklärende Fortsetzung gab; dadurch wären die Zurückweisungen Prof. Keibels unmöglich geworden.

Ausdrücklich muß ich auch hier erklären, wie ich es in meinen Vorträgen stets tat und tue, daß ich einen Zusammenhang der heutigen Fauna und Flora mit der zuerst auf Erden hervorgetretenen durchaus anerkenne! Mir ist nur die Annahme, daß „zufällig“ neue Eigenschaften hinzugetreten seien, eine Unmöglichkeit, weil ich dadurch in keiner Weise erklären kann, wie es kommt, daß die meisten zweckmäßigen Einrichtungen nicht für die freilebende Form zweckdienlich sind, sondern ausschlieBlich nur zur Erhaltung des zukünftigen Geschlechtes dienen. Dazu gehöıt u. a. auch das von mir besprochene Amnion, das sicher nicht als ein Organ aufgefaßt werden kann, das im Kampfe ums Dasein langsam und zufällig hervortrat. Auf solche Einrichtungen, die sich in Hülle und Fülle finden, weise ich in meinen Vorträgen ernst und streng wissenschaftlich hin. Das ist mein unbestreitbares Recht und meine einfache Pflicht! 